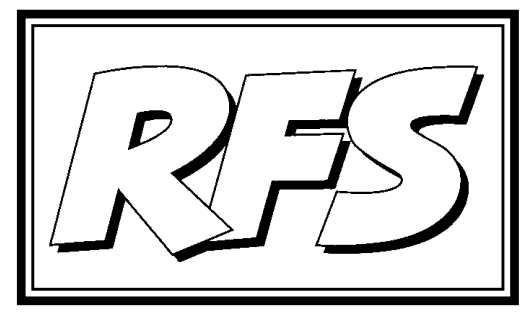

Revista de Fomento Social, 60 (2005), 113-118

\title{
Aniversario de Monseñor Romero. ¿Y nosotros?
}

\author{
(Palabras clave: Monseñor Romero, Aniversario, InJusticia, OpCión por \\ LOS POBRES, ESPERANZA) \\ (KEY WORDS: MONSIGNOR ROMERO, ANNIVERSARY, INJUSTICE, OPTION IN \\ FAVOUR OF THE POOR, HOPE)
}

\begin{abstract}
"Mi posición es el deber de un pastor que siente la alegría, al mismo tiempo que la angustia, de vivir con su pueblo y desde el pueblo, fiel a la voluntad de Dios, caminando por un camino que sea verdaderamente los caminos del Señor" (9.10.1977).
\end{abstract}

En estas palabras aparecen los dos referentes de la vida de Monseñor Romero, "Dios y el pueblo", y cómo se relacionó con ellos, "caminando los caminos del "Señor". Para nosotros celebrar a Monseñor sólo se podrá hacer, entonces, mirando a Dios y al pueblo, y-añadimos- "caminando los caminos

1 Universidad Centroamericana (UCA) de San Salvador. 
de Monseñor". Lo queremos explicar en tres puntos: el seguimiento, más allá de gestos y palabras; la esperanza contra el desencanto; el amor al pueblo sufriente contra el egoísmo personal e institucional.

\section{El seguimiento de Monseñor, más allá de gestos y palabras}

Muchos celebrarán este año a Monseñor, en eucaristías, charlas y conferencias, exposiciones y conciertos, y en la gran vigilia del 2 de abril. Lucirán camisetas, colgarán afiches y se emocionarán al escuchar su palabra por la YSUCA. De fueran vendrán centenares, y en total serán miles los que participarán en el aniversario. Y nada digamos si se da alguna señal de que la beatificación está cerca. Pero, con todo, falta una cosa, como ocurrió en los inicios del cristianismo. Los primeros cristianos oraban a Cristo, lo celebraban en la eucaristía y lo proclamaron "Mesías", "Hijo de Dios", "Señor", pero sólo con eso faltaba lo principal, el seguimiento. "Sígueme" es la primera y última palabra de Jesús a Pedro.

También a Monseñor lo celebramos y lo proclamamos "pastor", "profeta" y "mártir", y esperamos proclamarlo "santo". Pero, sin su seguimiento, falta lo fundamental -y paso previo- es la humildad de la conversión. "Una Iglesia que sólo mira pecado en los otros y no mira la viga que lleva en su propio ojo, no es la auténtica Iglesia de Cristo" (8.7.1979).

El seguimiento es una forma de vivir y de hacer. Empezamos preguntándonos qué es lo que hay que hacer hoy en el seguimiento de Monseñor, y comenzamos con la palabra de verdad, que, por ello, fue y es palabra de denuncia profética. Han cambiado las cosas en estos 25 años, pero Monseñor Romero nos sigue remitiendo certeramente a las idolatrías y pecados de nuestro mundo. 1) La idolatría del dinero, la oligarquía de siempre, 2) la idolatría del poder militar, más callada aquí y más clamorosa en Estados Unidos, 3) la connivencia de unos partidos políticos con la injusticia y la irresponsabilidad de buena mayoría de ellos ante el sufrimiento de las mayorías, a lo que hay que añadir la corrupción, 4) el imperialismo de Estados Unidos, en el comercio, en nuestra política internacional y, sobre todo, en los pseudovalores que nos impone: individualismo sin pensar en los otros, éxito contra los otros, buen vivir insensibles ante el mal vivir de otros, 5) la corrupción de la administración de justicia, que, oficialmente, todavía no ha esclarecido ni siquiera quién mató a Monseñor, 6) los medios de comunicación, con la mentira, las verdades a medias, el encubrimiento, según los casos, 7) el falseamiento de la religión, el espiritualismo exagerado, que no es la vida 
con espíritu; el individualismo alienante, que no es la apropiación personal de la fe; el gregarismo que llena estadios, que no es la comunidad y el llevarse mutuamente; la infantilización de lo religioso, que no es la sencillez -como niños- ante el misterio de Dios. Y a estos males hay que añadir la espantosa violencia actual -de 8 a 10 homicidios diarios en los últimos tiempos-, el éxodo masivo de emigrantes...

Y hay que volver al anuncio de una buena noticia y trabajar por ello. Hay que recuperar la evangelización, en el sentido primigenio que tiene en Jesús: el anuncio de una buena noticia a los pobres, sin que la novedad en métodos y lenguaje sustituya a lo esencial. Hay que anunciar ese reino con credibilidad, sin pensar que hay cosas más importantes que hacer, algunas de ellas muy buenas, como la vida sacramental, otras ambiguas, como el sinnúmero de concentraciones, fiestas, jubileos, años dedicados a algo, como si hubiese miedo a dejar vacíos en el tiempo y ponernos ante Dios a la intemperie. Y otras son peligrosas y pueden llegar a ser pecaminosas: proselitismo competitivo, buscar triunfos, basarse en apoyos financieros en los ricos de este mundo. Y hay que recobrar la parcialidad de Dios y de su Cristo hacia los pobres de este mundo.

Hay que recuperar y promover la opción por los pobres, sin aguarla, arriesgando por ella, recordando y honrando a quienes la vivieron hasta el final: nuestros mártires; la praxis de la justicia; la organización del pueblo, en la sociedad y en la Iglesia. No hay por qué volver a los años 80 , lo que es imposible, pero sí hay que volver a la intuición fundamental: como Iglesia somos comunidad, cuerpo. Y para influir en la sociedad la comunidad eclesial debe estar relacionada con otras fuerzas sociales de la base.

Esto es difícil, pero por ahí comenzamos, pues en esto cojeamos. En eso era eximio Monseñor, y no se ve cómo podemos celebrarlo sin, al menos, plantearlo.

\section{Esperanza contra el desencanto}

En el país escasea la esperanza y abunda el desencanto. Una de las razones es que los líderes de todo tipo, con algunas excepciones, no toman en serio la realidad del país ni a sus gentes. Hoy Monseñor se desviviría por levantar el ánimo de la gente. Lo haría por amor y también ex officio: "La Iglesia sólo aporta un valor: la esperanza en los hombres" (18.2.1979). Eso es lo que anhelan muchos, pero les es difícil encontrarlo. 
En la sociedad civil pocas cosas, aun de las importantes, se toman con total seriedad. No abunda la responsabilidad ante el pueblo, ni la disponibilidad a darle cuenta de lo que se hace. Se puede afirmar casi cualquier cosa sin tener que verificar si es verdad o no, y se puede mentir sin sonrojarse. Parece que nada interesa en serio, a excepción del medro propio. Esto lleva a trivializar la vida social y personal, al desencanto.

Se dirá que hay cosas peores, pero no tomar las cosas con seriedad es un mal mayor de lo que se piensa, y además, la esperanza pierde sus fundamentos. Hoy Monseñor nos haría el reclamo: "sean serios". Nos diría también: "no caigan en la amnesia de lo importante, los mártires, por ejemplo, ni en la banalización del espíritu que promueve la industria del entretenimiento". Eso es la superficialidad, el "facilismo", que denuncia Ernesto Sábato. Es el reino del lucro del capitalismo de siempre.

También la Iglesia tiene que hacer examen de conciencia sobre si toma y tomamos las cosas en serio. K. Rahner habló del "invierno eclesial". También es un tópico hablar de la involución, "la marcha atrás con respecto al Vaticano II", que proclamó que somos pueblo de Dios, no un conglomerado, con una jerarquía por encima de los fieles; que nos pidió mirar al mundo y echar su suerte con él, con firmeza para correr riesgos y con confianza de que Dios también se mueve en él. Aquí entre nosotros nos toca más de cerca la marcha atrás de Medellín. A veces todavía se usa su lenguaje, pero las palabras ya no significan mucho: Iglesia de los pobres, inserción, inculturación, opción real por ellos, están palideciendo. La magnifica generación de obispos alrededor de Medellín, con Don Helder Cámara a la cabeza, no encuentra relevo, como grupo. Pero parece que no preocupa. En palabras de don Pedro Casaldáliga, "de la misma fe cristiana se está haciendo un recetario de milagros y prosperidades, refugio espiritualista ante el mal y el sufrimiento y un substitutivo de la corresponsabilidad, personal y comunitaria, en la transformación de la sociedad".

Esta falta de seriedad, la amnesia y banalización, es el precio a pagar -dirán algunos- para que triunfe un pragmatismo eficaz, que es lo único que puede salvar a la sociedad y garantizar una Iglesia de grandes números. Pero el precio a pagar es también la pérdida de esperanza, el desencanto. Nunca hubo más esperanza en nuestro país que cuando se tomaron las cosas en serio, pueblo e Iglesia. Donde falta esta seriedad, la gente intuye bien que sus problemas no interesan y se siente desprotegida.

Hoy Monseñor Romero seguiría denunciando la trivialización ambiental en que vivimos. Bien claro lo dijo en su tiempo. "El robar se va haciendo 
ambiente. Y al que no roba se le llama tonto" (18. 3.1979). "Se juega con los pueblos... Se juega con la dignidad de los hombres" (11.3.1979). Y sacó la conclusión que muchos sacan hoy: "estamos en un mundo de mentiras donde nadie cree ya en nada" (18.3.1979). Algo han cambiado los modos, pero el tomar las cosas en serio sigue brillando por su ausencia. Tras la política hay mucho espectáculo, bien pensado y mejor escenificado. Tras el lenguaje educado se esconde la pereza y la pobreza mental. Y los que están arriba, aquí, y más en el Norte, se llenan la boca gritando "¡democracia, democracia!", esperando como respuesta de la audiencia el aplauso, sin acabar de decir qué es democracia y cuánto hay de ella. Todo ello abona el desencanto, es un atentado a la esperanza.

Para Monseñor, también la lglesia debe tomar con seriedad su ser y hacer. No disimulaba sus limitaciones: "sería triste una Iglesia que sólo condena, que sólo mira pecados fuera de ella, sin reconocer que también ella es pecadora" (8.7.1979). Ni se contentaba con lo fácil: "predicar es relativamente fácil, pero vivir lo que se predica... Entonces surgen los conflictos” (16.7.1978).

Monseñor se mantuvo firme en medio de inmensas dificultades. Tomó las cosas absolutamente en serio, hablaba desde lo último, y por eso decía: "en nombre de Dios y de este sufrido pueblo, cuyos lamentos suben hasta el cielo cada día más tumultuosos, les suplico, les ruego, les ordeno, ¡cese la represión!" (23.3.1980). Quien así habla puede decir también:

\footnotetext{
"Verán queridos pobres, queridos oprimidos, queridos marginados, queridos hambrientos, queridos enfermos, que ya está fulgurando la aurora de la resurrección. Para nuestro propio pueblo también ha de llegar esa hora, hermanos. Y hemos de esperarla, como cristianos, no sólo en dimensiones políticas coyunturales, sino en dimensiones de fe y esperanza. Esta es la misión que yo estoy cumpliendo. Y por eso mi palabra quiere ser una palabra de esperanza y de fe en Jesucristo" (11.11.1979).
}

\section{El amor al pueblo sufriente contra el egoísmo personal e institucional}

El pueblo le creía en definitiva porque Monseñor fue hombre de un gran amor. Hace muchos años escribió Jürgen Moltmann: "No toda vida es ocasión de esperanza, pero sí lo es la vida de Jesús quien, por amor, tomó sobre sí la cruz". A Monseñor le impactó el amor que vio en la generosidad de muchos, y por esto tuvo él esperanza. Y dio esperanza a otros porque los amó.

Ante el pueblo sufriente, muchas veces como oveja sin pastor, celebrar a Monseñor Romero significa hoy levantar el espíritu de la gente y, para ello, amarlo. Dicho con sus palabras, hay que llevarle cercanía: “¡Cómo me da 
gusto en los pueblecitos humildes que las gentes y los niños se agolpan a uno, vienen a uno!" (12.8.1979). Consuelo: "Para mí son nombres muy queridos: Felipe de Jesús Chacón, 'Polín'. Yo les he llorado de veras" (15.2.1980). Dignidad: "Ustedes son el divino traspasado" (19.7.1977). Gozo: "Con este pueblo no cuesta ser buen pastor" (18.11.1979). Esperanza: "Estoy seguro de que tanta sangre derramada y tanto dolor no será en vano" (27.1.1980). Y todo eso con humildad: "Yo creo que el obispo siempre tiene que aprender del pueblo" (9.9.1979), y con credibilidad: "El pastor no quiere seguridad mientras no se la den a su rebaño" (22.7.1979).

Dos palabas para terminar. Más de uno dirá: "Monseñor amó a su pueblo, pero se equivocó. La esperanza no fructificó" -y lo mismo puede decirse de Jesús de Nazaret. Ese es un juicio basado en el desencanto que producen todos los inmediatismos que fomentan dogmáticos y pragmáticos. Pero para quien tiene aliento y mira lejos, ni Monseñor ni Jesús se equivocaron. Pusieron en marcha una esperanza, con altibajos en la historia, pero esperanza al fin, de la que viven muchos, los pobres sobre todo y quienes con ellos se solidarizan. En estos días de aniversario la pregunta es si nos apuntamos o no a ese movimiento de esperanza que desencadenó Monseñor. No ofreció ni ofrece recetas, pero sí ofrece caminos, luces, impulsos. Y al poner a producirlos, se mantiene la esperanza

Y una última cosa, de la que, en definitiva, sólo pueden hablar "con autoridad" quienes han vivido situaciones cercanas a la de Monseñor. A mediados de los años ochenta las madres de desaparecidos me pidieron que dijera una misa para recordar a Monseñor Romero. Cuando estaba para salir de mi casa, una sencilla trabajadora de la UCA me dijo: "en la misa de Monseñor, recuerde a mi hijo". Su hijo había sido asesinado por los cuerpos de seguridad. Pensar que estaba con Monseñor era su mayor consuelo. Pues bien, no sabemos que ocurrirá dentro de otros 25 años, pero hoy todavía hay mucha gente que el 24 de marzo recuerda a sus hijos e hijas, esposos, padres, hermanos y hermanas, que también fueron asesinados. Le piden a Monseñor que cuide de ellos.

A Monseñor le hablan como se habla a un padre. Quizás le piden favores, "milagros", pero pienso que no lo hacen porque ven en Monseñor a un santo "milagrero", con poder, sino porque ven en él a un hombre bueno, alguien que les quiso y les quiere de verdad. Y no sólo eso. "Con Monseñor Romero Dios pasó por El Salvador", como dijo el Padre Ellacuría. Ver así las cosas ocurre "en lo escondido", pero es lo importante, pienso, en este XXV aniversario. 